\title{
PALÁCIOS PARA UMA RAINHA: D. MARIANA VITÓRIA DE BOURBON (1718-1781) ENTRE ESPANHA E PORTUGAL
}

\author{
Paulo Drumond Braga \\ (Cátedra Infante D. Henrique para os Estudos Insulares Atlânticos e a \\ Globalização/ Universidade Aberta)
}

\section{RESUMO}

D. Mariana Vitória de Bourbon (1718-1781), infanta espanhola e rainha de Portugal, habitou sucessivamente em Espanha, França e Portugal e, no ocaso da vida, passou cerca de um ano no seu país natal. Conheceu numerosos palácios nesses três reinos, nomeadamente Aranjuez, Escorial, Real Alcazar de Madrid, Palácio do Oriente (Espanha), Louvre e Versailles (França), Mafra, Queluz, Vila Viçosa, Paço da Ribeira, em Lisboa, e a Real Barraca, igualmente em Lisboa (Portugal).

PALAVRAS CHAVE: D. Mariana Vitória de Bourbon, Portugal, Espanha, França, palácios reais.

\section{PALACES FOR A QUEEN: MRS. MARIANA VITÓRIA OF BOURBON (1718-1781) BETWEEN SPAIN AND PORTUGAL}

\begin{abstract}
D. Mariana Vitória de Bourbon (1718-1781), Spanish Infanta and Queen of Portugal, lived successively in Spain, France and Portugal and, at the end of life, spent about a year in her native country. She knew many palaces in these three kingdoms, namely Aranjuez, Escorial, Real Alcazar of Madrid, Royal Palace of Madrid (Spain), Louvre and Versailles (France), Mafra, Queluz, Vila Viçosa, Paço da Ribeira, in Lisbon, and Real Barraca, also in Lisbon (Portugal).
\end{abstract}

KEY WORDS: D. Mariana Vitória de Bourbon, Portugal, Spain, France, royal palaces. 
Filha de Filipe V e de sua segunda mulher, Isabel Farnesio, reis de Espanha, D. Mariana Vitória de Bourbon nasceu em Madrid, a 31 de março de $1718^{1}$. Nos primeiros tempos da sua vida, o quotidiano da infanta foi o normal e o esperado, acompanhando os pais nas idas e vindas entre Aranjuez, Escorial e Madrid. Em dezembro e janeiro, a corte estanciava no Real Alcazar de Madrid, a velha residência que Filipe $\mathrm{V}$ substituiu depois pelo sumptuoso palácio do Oriente. Em fevereiro, mudava-se para o Bom Retiro. A páscoa era passada em Aranjuez e o Corpo de Deus em Madrid. No verão, estavam primeiro no Escorial (seis semanas) e depois no Pardo. Em princípios de dezembro, regressavam a Madrid. A partir de 1720, as estadas no Pardo foram substituídas pelas de Valsaín, onde Filipe V supervisionava as obras do palácio de Santo Ildefonso ${ }^{2}$.

Sendo ainda muito criança, D. Mariana Vitória foi destinada a casar-se com Luís XV, rei de França. Ao mesmo tempo, negociou-se o enlace de seu meio irmão mais velho, Luís, à época herdeiro do trono de Espanha, com Luísa Isabel, filha do duque de Orléans, regente de França na menoridade do soberano. A troca das princesas deu-se em janeiro de 1722, na ilha dos Faisões ou das conferências, no meio do rio Bidasoa ${ }^{3}$.

Instalada em Paris, a rainha princesa, como passou a ser conhecida, habitou inicialmente no palácio do Louvre, ao passo que Luís XV manteve a sua residência nas Tulherias. Em junho do mesmo ano de 1722, D. Mariana Vitória mudou-se para Versailles e aqui foi acomodada nos chamados apartamentos da rainha, que haviam sido ocupados por sua bisavó Maria Teresa, mulher de Luís XIV, e depois por sua avó, Maria Ana Cristina Vitória da Baviera ${ }^{4}$. Ali permaneceu até à sua saída de França.

O que parecia ser um conto de fadas rapidamente se esfumou. Em 1725, D. Mariana Vitória, com sete anos de idade, regressou a Espanha. O motivo foi puramente de ordem política: com a morte do duque de Orléans, em finais de 1723, o novo homem forte de França, o duque de Bourbon, Luís Henrique de BourbonCondé, começou a equacionar várias questões: se Luís XV morresse em filhos, a Coroa caberia ao novo duque de Orléans, Luís. Por outro lado, a 10 de janeiro de 1724, Filipe V de Espanha abdicara e receava-se que pudesse estar interessado na Coroa de França. Nesta perspetiva, era, pois, urgente que Luís XV, que completara

\footnotetext{
${ }^{1}$ Retomo no presente texto o que anteriormente escrevi em Paulo Drumond Braga, A Rainha Discreta. Mariana Vitória de Bourbon (Lisboa: Círculo de Leitores, 2014).

${ }^{2}$ Henry Kamen, Felipe V. El Rey que reinó dos veces (Madrid: Temas de Hoy, 2000), 171.

${ }^{3}$ Margarita Torrione, Lucienne Domergue, Reyes Escalera Pérez, José Miguel Morales Folguera, Marion Reder Gadow, Crónica Festiva de dos Reinados en la Gaceta de Madrid (1700-1759) (Toulouse: Universidade de Toulouse-Le Mirail, Paris: Ophris, 1998), 105. Sobre este tipo de viagens, cfr. María de los Ángeles Pérez Samper, "Princesas en camino", Estudis. Revista de Historia Moderna 39 (2013), 941.

${ }^{4}$ Alexandre Maral, Le Roi, la Court et Versailles. Le Coup d'Eclat Permanent. 1682-1789 (Paris: Perrin, 2013), 122-123.
} 
14 anos a 15 de fevereiro de 1724, assegurasse a sucessão da Coroa. Como D. Mariana Vitória tinha somente seis anos, considerou-se que o tempo que importava esperar para o casamento ser consumado e, consequentemente, nascer um herdeiro, era demasiado longo. Ou seja, havia que escolher uma nova mulher para Luís XV. Tal implicava devolver a infanta-rainha a Espanha ${ }^{5}$.

Embora Filipe $\mathrm{V}$ tenha, compreensivelmente, reagido muito mal à decisão francesa, tudo acabou por se concretizar. A 5 de abril de 1725, D. Mariana Vitória deixou para sempre Versailles. A 17, já entregue ao representante enviado por seu pai, o marquês de Santa Cruz, atravessou a fronteira ${ }^{6}$. A 29, atingiu Guadalajara, onde finalmente se avistou com os pais, que na véspera haviam deixado Aranjuez. A 30 de maio, deu-se a entrada em Madrid, com grande solenidade ${ }^{7}$.

Várias fontes consideram que D. Mariana Vitória conservou até à morte uma enorme mágoa contra a França, aludindo um autor gaulês a «má vontade à nossa nação, o que frequentemente manifestava» ${ }^{8}$. Outros usaram expressões como «aversão prodigiosa contra a corte de França» ${ }^{9}$, «rancor contra a nação francesa» ${ }^{10} \mathrm{e}$ «ódio invencível pela nação francesa» ${ }^{11}$. Tal não era totalmente verdade, já que a um diplomata que lhe comunicou, em junho de 1756, que a França chegara à paz com a Áustria, D. Mariana Vitória referiu-se a Luís XV como o tronco da sua família ${ }^{12}$. Em janeiro de 1757, comentou, em carta a Isabel Farnesio, o «horrível atentado» contra o soberano francês, referindo: "gostaria de saber o que é que o fez cometer um tão grande crime», dizendo recear que fosse algum herético, por motivos religiosos ${ }^{13}$. Em 1767, fez a um outro embaixador gaulês numerosas perguntas sobre Luís XV e a

${ }^{5}$ Alfred Braudillart, Philippe $V$ et la Cour de France d'après des Documents Inédites tirès des Archives Espagnols de Simancas et d'Alcalá d'Henarés et des Archives du Ministére des Affaires Étrangères à Paris, tomo III, (Paris: Fitmin-Didor, 1890), 43-173; Caetano Beirão, Cartas da Raínha D. Mariana Vitória para a sua Família de Espanha que se encontram nos Arquivos Histórico de Madrid e Geral de Simancas, vol. I, (Lisboa: Empresa Nacional de Publicidade, 1936), L-LIX; Michel Antoine, Louis XV (Paris: Hachette, 2006), 150-159.

${ }^{6}$ Simancas, A.G.S., Estado, legajo 7161.

7 Torrione, Domergue, Escalera Pérez, Morales Folguera, Reder Gadow, Crónica Festiva, 128-130.

${ }^{8}$ Conde de Saint Priest, "Um campanha militar. 1762. Uma missão diplomática. 1763-1766", Portugal nos Séculos XVII \& XVIII. Quatro Testemunhos (Lisboa: Lisóptima, 1989), 156

${ }_{9}$ Charles Dumouriez, État Présent du Royaume de Portugal en l'Année MDCCLXVI (Lausanne: François Grasset, 1775), 236.

${ }^{10}$ Giuseppe Gorani, Portugal. A Corte e o País nos anos de 1765 a 1767 (Lisboa: Lisóptima, 1989), 196.

11 Marquis de Bombelles, Journal d' un Ambassadeur de France au Portugal. 1786-1788, (Paris: Fundação Calouste Gulbenkian, 1979), 40.

12 Visconde de Santarém, Quadro Elementar as Relações Politicas e Diplomaticas de Portugal com as Diversas Potencias do Mundo, tomo VI (Paris: J. P. Aillaud, 1864), 89.

13 A.H.N., Estado, leg. 2512, doc. 87. Sobre a correspondência entre a rainha e sua mãe, cfr. María Victoria López-Cordón-Cortezo, "Mariana Victoria de Portugal: una infanta y muchas cartas", Pedralbes 36 (2016), 17-53. 
restante família real francesa ${ }^{14}$. E, em junho de 1774 , lastimou, em carta a Carlos III, a morte do rei de França, «nosso primo», classificando-a como «coisa lamentável» ${ }^{15}$. Ao mesmo tempo, no dizer Jean-François de Bourgoing, que era, em 1777-1778, secretário da legação francesa em Espanha, «mantinha a recordação dos mínimos detalhes relativos à sua estada em França e, ao fim de 55 anos, lembrava-se das estátuas do jardim de Versailles, das alamedas do parque, etc., como o poderia fazer no dia seguinte à sua partida» ${ }^{16}$.

A 27 de dezembro de 1727, aos nove anos de idade, D. Mariana Vitória casou, em Madrid, com o príncipe do Brasil, D. José, herdeiro da Coroa de Portugal. A 19 de janeiro de 1729, deu-se uma troca de princesas: a filha de Filipe V rumou ao seu novo reino e para Espanha seguiu Maria Bárbara, filha de D. João V, já matrimoniada com o futuro rei Fernando VI. O casamento de D. Mariana Vitória foi consumado em 1732, no dia em que completou 14 anos de idade ${ }^{17}$. Deu à luz quatro filhas, D. Maria I (1734), D. Maria Ana Francisca Josefa (1736), D. Maria Francisca Doroteia (1739) e D. Maria Francisca Benedita (1746). Mas esteve grávida pelo menos mais seis vezes, abortando sempre $(1733,1741,1743,1743,1744 \text { e } 1752)^{18}$. Em 1750, seu marido tornou-se soberano reinante de Portugal, consequentemente, D. Mariana Vitória assumiu a dignidade de rainha consorte.

Em termos de organização do espaço no quotidiano, no tempo de D. José I, os membros da família real ausentavam-se de Lisboa, entre os primeiros dias de janeiro e 16 do mesmo mês, estanciando em Calhariz, Pancas e Pinheiro, onde a caça os ocupava. Assistiam depois ao tríduo do desagravo do desacato de Santa Engrácia, entre 16 e 18, saindo para Salvaterra, de novo para se entreterem em atividades cinegéticas. Regressavam depois da Páscoa, indo por vezes 15 dias para Almeirim, uma vez mais para a caça. Passavam o verão em Queluz - onde celebravam o São João e o São Pedro, com as magníficas festas organizadas pelo infante D. Pedro - e Mafra era a escolhida para o período de 1 a 15 de outubro. Ocasionalmente iam também a Vila Viçosa ${ }^{19}$.

Depois do terramoto de Lisboa de 1 de novembro de 1755, o palácio da Ribeira foi destruído. Como D. José I se recusou, até à morte, a voltar a viver em

\footnotetext{
14 Visconde de Santarém, Quadro Elementar as Relacoenes Politicas e Diplomaticas de Portugal com as Diversas Potencias do Mundo, tomo VII (Paris: J. P. Aillaud, 1865), 54-55.

15 A.G.S., Estado, leg. 7297.

${ }^{16}$ [Pierre Marie Félicité Dezoteux, barão de Comartin], Voyage du ci-devant Duc de Chatelet en Portugal, tomo I (Paris : Arthus-Betrand, 1808), 95-96, nota 1.

${ }_{17}$ Braga, A Rainha, 44-64.

${ }_{18}$ Braga, A Rainha, 83-107.

${ }^{19}$ Filipe Folque de Mendonça, O Cardeal Patriarca de Lisboa Dom José de Mendonça. O Homem e o seu Tempo (1725-1808) (Lisboa: Universidade Lusíada, 2010), 444-445; Jeremy Black, "Portugal in 1775. The letters of Thomas Pelham", The British Historical Society of Portugal 14 (1987), 51; José de Castro, O Cardial Nacional (Lisboa: Agência Geral das Colónias, 1943), 243-247; Nuno Gonçalo Monteiro, D. José na Sombra de Pombal (Lisboa: Círculo de Leitores, 2006), 66 e 212.
} 
casas de alvenaria, a família real ficou a habitar, provisoriamente, «em barracas de campanhas, uma légua distante da cidade para a parte do ocidente, onde estão os jardins reais ${ }^{20}$. Às mesmas se referia D. Mariana Vitória em carta a Isabel Farnesio, em junho de 1756 , dizendo que a sua «nova casa» era «muito bonita e grande» ${ }^{21}$. No mês seguinte, comentou: «encontro-me muito comodamente e com a mais bela vista do mundo» ${ }^{22}$. A partir de março de 1757 , passaram para as chamadas reais barracas da Ajuda, feitas de madeira ${ }^{23}$. A rainha de Portugal descreveu esse novo alojamento como «muito bonito e cómodo» ${ }^{24}$. Ali tinha D. Mariana Vitória os seus aposentos, onde não faltava uma casa das embaixatrizes, para dar audiência às mulheres dos diplomatas estrangeiros, uma livraria e um «casa das gaiolas». Esta mostrava o seu gosto por aves, nomeadamente exóticas ${ }^{25}$.

No dia 24 de fevereiro de 1777, ao fim de quase um quarto século como rainha consorte - em que por duas vezes fora por D. José I encarregada da regência do reino ${ }^{26}-$ D. Mariana Vitória enviuvou. A primogénita do casal subiu ao trono com o nome de D. Maria I. Iniciava-se uma nova fase na vida da filha de Filipe V e de Isabel Farnesio.

Perto do final da vida, entre outubro de 1777 e novembro de 1778, D. Mariana Vitória esteve em Espanha, revendo o irmão Carlos III - com quem nunca deixara de contactar por via epistolar - e ajudando a pacificar as duas monarquias ibéricas. A hipótese do encontro surgiu numa carta que a rainha viúva escreveu ao soberano espanhol a 20 de maio de 1777: «alegro-me muitíssimo, irmão da minha vida, do que me dizes parecer-te que esta viagem, em lugar de causar dano, faria muito proveito assim o creio eu também, mas permite-me irmão de minhas entranhas, diz-me como faremos tudo isto». Ou seja, a rainha de Portugal solicitava a Carlos III que estipulasse o tempo, o lugar e o modo como tudo se deveria processar. E assinalava: «não quero que digam aqui que ando inventando jornadas e outras coisas». D. Mariana Vitória concluía evidenciando que, assim que em Portugal consentissem, iria de imediato, teria apenas de preparar a viagem ${ }^{27}$. Cinco dias depois, continuava a insistir nos mesmos tópicos e sublinhava um aspeto: a jornada a Espanha era ainda mantida em segredo, pois «a rainha minha filha comunica tudo o

20 António Pereira de Figueiredo, Diario dos Successos de Lisboa desde o Terramoto até o Exterminio dos Jesuitas (Lisboa: Francisco Borges de Sousa, 1766), 2.

${ }^{21}$ A.H.N., Estado, leg. 2512A, doc. 55.

22 A.H.N., Estado, leg. 2512A, doc. 63.

${ }^{23}$ Monteiro, D. José, 84-85 e 213.

24 A.H.N., Estado, leg. 2512, doc. 87.

${ }^{25}$ Maria Isabel Braga Abecassis, A Real Barraca. A Residência na Ajuda dos reis de Portugal após o Terramoto (1756-1794) (Lisboa: Tribuna da História, 2009), 66.

${ }^{26}$ A primeira foi de 7 de setembro a 12 de dezembro de 1758 e a segunda de 29 de novembro de 1776 a 24 de fevereiro de 1777. Cfr. Braga, A Rainha, 142-144 e 204-211.

${ }^{27}$ A.H.N., Estado, leg. 3410, expediente 1, n. ${ }^{\circ} 11$ (1). 
que se passa com a corte» e as coisas de importância eram sempre tratadas com o marido, D. Pedro III ${ }^{28}$.

A 24 de junho, numa carta do embaixador de Portugal em Espanha, D. Francisco Inocêncio de Sousa Coutinho, a Aires de Sá e Melo, aludia-se por sua vez à hipotética deslocação de D. Mariana Vitória: Carlos III, depois de ter lido uma carta em que a rainha-mãe de Portugal se queixava de «moléstia do estômago», dissera: «eu desejo ver minha irmã, ou sua majestade venha cá ou eu irei lá». Os diplomatas presentes à cena ficaram «pasmados». O próprio Sousa Coutinho o deve ter ficado, respondendo: «que honrando as províncias fronteiras com a sua real presença poderia conseguir este gosto sem que lhe faltasse a diversão da caça de que abundavam aqueles lugares». Carlos III perguntou-lhe então a que distância ficavam Queluz, Sintra e Mafra umas das outras «e sempre repetia o mesmo, que queria ver sua irmã pelo grande amor que lhe tinha e a toda a sua real família de sorte que visto o exemplo do imperador em Paris não houvera novidade vendo a el rei católico em Lisboa» ${ }^{29}$.

A 7 de julho, o mesmo embaixador relatou a Carlos III o «alvoroço» com que D. Maria I e D. Mariana Vitória haviam recebido a novidade «de que poderiam ter o gosto de vê-lo»» ${ }^{30}$. A 4 de agosto, o rei de Espanha voltou a pedir a Coutinho que transmitisse à irmã o «desejo de vê-la» ${ }^{31}$. A 9 do mesmo mês, a viagem ainda era incert $^{32}$. A 26 de agosto, o diplomata referia para Lisboa o contentamento de Carlos III «de ver a sua augusta irmã» ${ }^{33}$. E três dias depois aludia aos preparativos que começavam a ser feitos em Espanha ${ }^{34}$. A 13 de setembro, a ida de D. Mariana Vitória a Espanha já tinha sido anunciada em Lisboa e a informação era transmitida a Londres por Robert Walpole ${ }^{35}$.

Entretanto, Carlos III conversara com Coutinho, refletindo «sobre os sucessos que foram necessários para ver-se depois de 48 anos e que só dependera de Deus» ${ }^{36}$. A 16 de setembro, o embaixador português aludia aos preparativos que avançavam. O soberano designara várias pessoas para servirem D. Mariana Vitória, desde o mordomo-mor, o conde de Banhos - que o fora de Isabel Farnesio -, a guardas para os caminhos, passando por médicos, boticários, cirurgião e um secretário. Pensava-se ainda em escolher cavalos «que pareçam melhor a sofrer os

28 A.H.N., Estado, leg. 3410, expediente 1, n. 11 (2).

${ }^{29}$ A.N.T.T., Ministério dos Negócios Estrangeiros, caixa 629.

30 A.N.T.T., Ministério dos Negócios Estrangeiros, caixa 629.

31 A.N.T.T., Ministério dos Negócios Estrangeiros, caixa 629.

${ }^{32}$ C. R. Boxer, Descriptive List of the State Papers Portugal 1661-1780 in the Public Record Office London, vol. III (Lisboa: Academia das Ciências de Lisboa, 1983), 224.

33 A.N.T.T., Ministério dos Negócios Estrangeiros, caixa 629.

34 A.N.T.T., Ministério dos Negócios Estrangeiros, caixa 629.

35 Boxer, Descriptive, 226.

36 A.N.T.T., Ministério dos Negócios Estrangeiros, caixa 629. 
tiros», ou seja, a dificuldade das jornadas. A cozinha e a repostaria foram igualmente preparadas. No palácio real (Madrid) e no Escorial tratou-se dos aposentos: «se the destina o quarto das rainhas». Comentário do diplomata: «Nem se poupa nada que fosse contribuir ao prazer desta real visita com uma grandeza própria dos dois augustos monarcas». Ao mesmo tempo, Sousa Coutinho, recordando o facto de ser necessário «dar uma ideia da sua polidez e da sua riqueza» (de Portugal, entenda-se), assinalava a necessidade de os coches idos com D. Mariana Vitória serem «luzidos», «para que os Espanhóis os vissem». Mas a rainha manifestou desejo de ir em sege, ficando os coches para a comitiva. O embaixador manifestou ainda preocupação com outro aspeto protocolar: conviria que ele próprio se deslocasse até à fronteira, já que Carlos III ordenara que o seu embaixador em Portugal viesse até onde D. Mariana Vitória desejasse: «parecia que a rainha nossa senhora teria uma igual atenção à sua augusta mãe» ${ }^{37}$. A 26 , Coutinho voltou a dizer que «a magnificência e grandeza reina em tudo» ${ }^{38}$.

Um pouco mais tarde, Rodrigo de Sousa Coutinho, filho do referido embaixador de Portugal em Espanha, e então um jovem de 22 anos, confirmou: «a magnificência com que el rei trata sua irmã é indizível», especificando:

são tantos os coches da comitiva que não cabendo em Badajoz estão debaixo dos arcos da ponte; são infinitas as seges, caleças, carros de matos; há mais de 50 mesas prontas para comerem e de diferentes graduações; pelo caminho se vêm fazendo pão excelente para a comitiva; até vem moinhos para se moer trigo; vem água de Madrid para a rainha, para que não beba água má destas terras, onde há muita má39.

Um pouco mas tarde, acrescentou:

só da casa eram 12 coches, além de mais de 80 de aluguer, a que chamam coelheiras; era infinito o número de gente que comia e vinha à custa de el-rei [Carlos III]. Creio que em tudo havia mais de 2000 pessoas. O número de cozinheiros passava de 60 e até o dos depenadores de aves passavam de 20 . Os cozinheiros, aprestos de cozinha, armadores e armações de casa se dividiram em duas turmas, as quais mutuamente se revezavam, de forma que os que serviam ao jantar iam servir ao outro dia também ao jantar e os da noite ao outro dia à noite e isto com tal ordem que quando a rainha chegava, já a casa estava armada, o comer feito e tudo pronto para o universo em peso que fosse ${ }^{40}$.

37 A.N.T.T., Ministério dos Negócios Estrangeiros, caixa 629.

38 A.N.T.T., Ministério dos Negócios Estrangeiros, caixa 629.

${ }^{39}$ Andrée Mansuy-Diniz Silva, Portrait d'un Homme d'État: D. Rodrigo de Sousa Coutinho, Comte de Linhares. 1755-1812, vol. I (Lisboa: CNCDP; Paris: Centro Cultural Calouste Gulbenkian, 2002), $384-$ 385.

40 Silva, Portrait, 389 
Como reagiu Portugal à notícia de que Mariana Vitória ia viajar até Espanha? Teresa de Melo Breyner, filha da camareira-mor da rainha, Isabel Josefa de Breyner de Meneses, comentou com a futura marquesa de Alorna ser a viagem uma «novidade repentina para o público», que vinha dando «ocasião a muitas mentiras» ${ }^{41}$. O marquês de Pombal, já afastado da política, escreveu ao genro, o morgado de Oliveira, futuro $1 .^{\circ}$ conde de Rio Maior:

$\mathrm{Na}$ cidade de Coimbra e nesta vila [Pombal] corre geralmente que a sereníssima senhora rainha-mãe passa a Castela. Fico atónito, sem poder atinar a que hei de atribuir esta jornada, se é certa. Lembrando-me o caso da rainha D. Catarina, e do que sobre se lhe representou na carta e papel que constituem a prova n. ${ }^{\circ}$ III do tomo $8 .^{\circ}$ da Dedução Chronologica ${ }^{42}$.

A 7 de outubro, já dizia: «A jornada (já hoje pública) da sereníssima senhora rainha-mãe, que se deve seguir à de Vila Viçosa, se tem qualquer dos dois objetivos que parece significar a recíproca alegria de ambas as duas cortes pode lisonjear muito as nossas esperanças». Um deles era o casamento de Carlos III com a única filha solteira de D. Mariana Vitória, D. Maria Ana Francisca Josefa, que já anteriormente se tinha tentado negociar, sem êxito, outro era «estabelecer entre ambas as cortes o sistema da perpétua paz que sempre entendi e fiz ver algumas vezes que era do interesse recíproco de uma e outra monarquia» ${ }^{43}$. Opinião manifestou ainda a prioresa de Carnide, Madre Teresa de S. José de Coração de Jesus, uma correspondente habitual de D. Maria I. A 15 de setembro de 1777, relatava à soberana que D. Mariana Vitória estivera no convento:

Sua mãe não falou diante de mim na jornada, mas disseram-me minhas tias, que lhes dissera não era capaz de lá ficar nem deixar seus filhos e netos, que ia pelos interesses do reino. Tenho pegado nesta palavra, para não gostar que intente ir, sem estar fixa a paz, o que se me afigura bem inconveniente.

Acrescentava depois: «Eu grande repugnância acho nesta jornada a Espanha e me tem entristecido, mas talvez sejam diversos os fins e que será conveniente esta» ${ }^{44}$. Ainda em setembro ou já em outubro, dizia: «Não se consuma, que o não quer a Nosso Senhor nem com a jornada de sua mãe» ${ }^{45}$.

Entretanto, a viagem começava a ser preparada do lado de Portugal. Da comitiva fizeram parte o $5 .^{\circ}$ conde de Vale de Reis, Lourenço Filipe de Mendonça e

\footnotetext{
${ }^{41}$ Raquel Bello Vázquez, "Uma Certa Ambição de Glória: Trajectória, Redes e Estratégias de Teresa de Mello Breyner nos Campos Intelectual e do Poder em Portugal (1770-1798)" (Tese de doutoramento, Universidade de Santiago de Compostela, 2005), 157.

42 Cartas do Marquês de Pombal (1777-1780) (Coimbra: Imprensa da Universidade, 1916), 23-24.

${ }^{43}$ Cartas do Marquês de Pombal (1777-1780), 25.

44 Alice Lázaro, O Reinado do Amor. Cartas Íntimas da Priora da Estrela para a Rainha Dona Maria I (1776-1780) (Lisboa: Chiado, 2013), 337-338.

45 Lázaro, O Reinado, 340.
} 
Moura, mordomo-mor de D. Mariana Vitória; o $6 .^{\circ}$ conde de Aveiras, Francisco da Silva Telo e Meneses, veador; Isabel Josefa de Breyner de Meneses, futura condessa de Ficalho, camareira-mor: a condessa de Lumiares, D. Juliana Xavier Bolteho, viúva do 1. ${ }^{\circ}$ conde, dama; D. Isabel da Gama, dama de honor; Teresa Gertrudes Capuers, açafata ${ }^{46}$.

Além destes, lugar ainda para o confessor, o capelão, o médico, o cirurgião e numerosos criados: criada do toucador, moça da retrete, engomadeira, dois varredores, quatro reposteiros, três varredores da câmara, um cozinheiro, um ajudante de cozinha, um arcabuzeiro, um moço de recados, um moço da botica, quatro moços de carga do guarda-roupa, um alveitar, moços da estrebaria, dois cocheiros, azemeleiros, ajudantes, moços de coche, moço da botica dos cavalos e 30 moços de cavalharice ${ }^{47}$.

Na referida carta de Teresa de Melo Breyner, filha da camareira-mor de D. Mariana Vitória, pode ler-se: «Eu estou melhor mas com a sensaboria de ver partir minha mãe dentro de poucos dias para Espanha, com a rainha-mãe, que ontem the perguntou se a queria acompanhar e lhe fez muitas expressões do gosto que tinha de que ela se sujeitasse a fazer-lhe companhia» ${ }^{48}$.

Ficou decidido que D. Maria I, D. Pedro III, o príncipe D. José, o infante D. João e a infanta D. Maria Ana Francisca Josefa acompanhariam D. Mariana Vitória ao Caia. Permaneceu em Lisboa, devido a uma «pequena moléstia», D. Maria Francisca Benedita ${ }^{49}$, o que foi lamentado pela rainha-mãe, escassos dias antes de partir, a 17 de outubro, em carta escrita da Ajuda a D. Maria I, onde rematava de uma forma que lhe era costumeira: «paciência» ${ }^{50}$.

D. Mariana Vitória parecia, entretanto, achar-se dividida entre a enorme vontade de se avistar com Carlos III e algum receio pela jornada propriamente dita, atendendo a que as suas condições de saúde estavam longe de ser as mais favoráveis e, na época, uma viagem como esta, mesmo feita com recurso ao que havia de melhor, era tudo menos confortável. A 15 de outubro, a prioresa de Carnide opinava em carta a D. Maria I: «saiba minha senhora que achei a sua mãe tímida para a jornada, por conta da cabeça, mas bem contente» ${ }^{51}$. Dois dias depois, era a própria D.

${ }^{46}$ José Pedro Ferrás Gramoza, Successos de Portugal. Memorias Historicas Politicas e Civis, tomo II (Lisboa: Tipografia do Diário da Manhã, 1882), 46; Silva, Portrait, 387.

${ }^{47}$ Eurico Gama, "Crónica da viagem da rainha mãe de Portugal, Dona Mariana Vitória de Bourbon, a Espanha, no Outono de 1777”, Ocidente 176 (1952), 244-245.

48 Bello Vázquez, "Uma Certa", 157.

${ }^{49}$ A.N.T.T., Ministério dos Negócios Estrangeiros, cx. 826.

${ }^{50}$ B.A., 54-X-7 (159).

51 Lázaro, O Reinado, 343. 
Mariana Vitória que, na citada carta a D. Maria I, dizia achar-se «com as minhas ânsias costumadas» ${ }^{52}$.

A partida deu-se a 21 desse mês de outubro ${ }^{53}$. A 27, chegou a comitiva a Elvas. Encaminhou-se depois para o Caia, «onde estava um numerosíssimo concurso de pessoas castelhanas e portuguesas, das vizinhanças de Elvas e Badajoz». Despediram-se então as figuras reais, «dando-se os últimos adeuses com tal ternura que provocarão um choro geral em todos os espetadores $\rangle^{54}$. No dizer de Rodrigo de Sousa Coutinho, D. Mariana Vitória «abraçou suas filhas e de repente estando o seu rosto banhado em lágrimas, disse ao cocheiro: ‘Anda homem' e ao mesmo tempo lhe ouviram estas belas palavras: 'Muito me deve meu irmão'. Palavras que indicam bem quanto é amável e terno o seu coração»» ${ }^{55}$.

Enquanto D. Mariana Vitória passou o rio, entrando em território espanhol, D. Maria I, D. Pedro III e restante família partiram para Vila Viçosa. Uma fonte descreveu o início da viagem da rainha-mãe:

Todos os cavaleiros e senhores de Badajoz e seus contornos, vestidos magnificamente e em boas, outros em péssimas carruagens, vieram obsequiar Sua Majestade, para mostrarem o grande contentamento que recebiam, e quiseram ter a honra de acompanhá-la, para o que concorreu Sua Majestade e fazendo a jornada muito devagar e permitindo que tudo fosse atrás do conde de Banhos e do marquês de Almodôvar, que a seguiam ${ }^{56}$.

A própria rainha o confirmou, a 28 de outubro, em carta escrita de Badajoz, a D. Maria I, onde, além de se congratular pela notícia de que a família portuguesa chegara bem a Lisboa, escrevia: «desde Caia até aqui me acompanhou infinita gente a pé e a cavalo» e «em toda a parte me fizeram infinita festa». Entre as pessoas a quem deu audiência, causou-lhe particular impressão certa fidalga: «parecia-me figura de ópera antiga» ${ }^{57}$. A 29 de outubro, em Meajadas - «terra que é horrível, tudo casas toscas» - anotou que a viagem até lá, vinda de Mérida - «cidade antiquíssima» durara seis horas. Jantara em público e «até tive um bispo sempre de luvas calçadas» e «um frade gordo de Guadalupe» ${ }^{58}$. A 31, em Almaraz, referia já ter trocado algumas palavras com o embaixador de Portugal em Espanha e manifestava a intenção de chegar ao Escorial no dia de S. Carlos ${ }^{59}$. Talvez por isso tenha, no dizer de Rodrigo

\footnotetext{
52 B.A., 54-X-7 (159).

${ }^{53}$ Jennifer Roberts, The Madness of Queen Maria. The Remarkable Life of Maria I of Portugal (Langely Burrell: Templeton, 2009), 63.

54 Gama, "Crónica", 241-242.

55 Silva, Portrait, 389.

${ }^{56}$ Gama, "Crónica", 241.

${ }^{57}$ B.A., 54-V-20 (8b).

58 B.A., 54-V-20 (8a).

${ }^{59}$ B.A., 54-V-20 (8c).
} 
de Sousa Coutinho, mandado apressar a jornada, «o que causou alguma desordem, ainda que na prontidão com que tudo se fazia, não se sentiu diferença» ${ }^{60}$. A 1 de novembro, D. Mariana Vitória voltou a falar «mais de uma hora» com o embaixador, no dizer do filho deste, que acrescentou: «pareceu-me que vinha alegre», comentando: «Que bela vista faziam hoje os coches e membros da comitiva pelo meio-dia, o sol mais claro que imaginar se pode» ${ }^{61}$.

Retomando as cartas da rainha-mãe à rainha reinante, verifica-se que a primeira, a 1 de novembro, descreveu Oropesa à filha: o castelo «pareceu-me de mouros encantados». $\mathrm{Na}$ vila, as casas eram «antiquíssimas, velhíssimas e muito feias», mais valendo "as nossas terras, ainda as mais miseráveis». A dado momento, um desabafo: «muitas saudades tenho tuas e de todos». Manifestava depois alguma preocupação: «estou com bastante receio das jornadas que me faltam», acrescentando: «que Deus me permita conservar vida para tornar para a vossa companhia»e ainda «Deus queira que eu torne viva para casa» ${ }^{62}$.

A 2, jantou em Talavera de la Reina, onde recebeu o arcebispo de Toledo. Um dos irmãos, o infante D. Luís enviou-lhe três galinholas acabadas de caçar ${ }^{63}$. Na noite de 2 para 3, dormiu em Cebolla, chegando, a 4, ao Escorial ${ }^{64}$. Aqui avistou-se com Carlos III, que a foi ver sem prévio aviso, acompanhado do primogénito, o futuro Carlos IV. "Vimos com grande ternura a particular e fina com que as duas majestades se abraçaram e com que conversaram quase uma hora, interrompendolhes muitas vezes os sentimentos do coração o uso da voz», disse em carta para Lisboa o embaixador português em Espanha ${ }^{65}$.

No dia seguinte, foi a própria D. Mariana Vitória que relatou a D. Maria I esse seu primeiro encontro com o irmão: «podes julgar o gosto que tive de o ver». $\mathrm{O}$ rei pareceu-lhe «muito velho mas bem conservado e forte» e, por outro lado, «um santo homem, muito amável». Já o futuro Carlos IV foi descrito como «moço alto, grosso, muito forte e não tão mal posto como nos tinham dito, branco, muito louro com olhos azuis, mas muito feio». Depois, avistou a restante família real. Da princesa das Astúrias, Maria Luísa de Parma, referiu: «não é muito grande, pouco é maior do que eu, estava sem donaire [elegância], com roupa francesa». D. Gabriel, outro filho de Carlos III, «tem muito má figura e cor, mas é muito vivo e agradável». Os demais infantes, António Pascual, irmão do anterior, e Luís, irmão da própria Mariana Vitória, foram descritos como «feios bastantemente». E rematava: «Todos me fizeram muita festa $[. .$.$] não me deixaram respirar toda a noite» { }^{66}$.

\footnotetext{
${ }^{60}$ Silva, Portrait, 389.

${ }^{61}$ Silva, Portrait, 387.

62 B.A., 54-V-20 (8d).

${ }^{63}$ A.N.T.T., Ministério dos Negócios Estrangeiros, caixa 629.

${ }^{64}$ A.N.T.T., Ministério dos Negócios Estrangeiros, caixa 629.

65 A.N.T.T., Ministério dos Negócios Estrangeiros, caixa 629.

66 B.A., 54-V-20 (8e).
} 
A 9, falou das constantes provas de amor de Carlos III, «O homem mais agradável que se pode imaginar» e referiu a infanta D. Maria Josefa, filha do monarca espanhol: «é muito feia, mas é muito viva e tem muito juízo». Anotou depois que, se não estivesse longe da família portuguesa, «estaria contentíssima». Referiu, seguidamente, que Sousa Coutinho lhe falara de um projeto de tratado entre a Espanha e a França, tendo pedido imediatamente a Carlos III que a esclarecesse a este respeito. Agradeceu ainda as gazetas que D. Maria I lhe enviara e terminou com um interessante pedido: «Disse a Martinho de Melo que me mande os periquitos e se houver na mesma quinta algum veadinho daqueles pequenos manda-mo também e tudo o que se puder achar de mais especial pois meu irmão gosta muito de toda a bicharia» ${ }^{67}$.

Segundo informou Francisco Inocêncio de Sousa Coutinho a 11, o quotidiano de D. Mariana Vitória era passado da seguinte forma: assim que Carlos III a sabia acordada, ia visitá-la, ajustando as atividades do dia. Quando chegavam da caça, que geralmente os ocupava diariamente, a família reunia-se e conversavam demoradamente. A infanta D. Maria Josefa «fica para fazer a partida [refere-se a jogo de cartas] e acompanha a Sua Majestade em todas as horas que a mesma senhora quer» ${ }^{68}$. Acrescente-se que chegou a haver uma manifestação de ciúmes por parte de Maria Luísa de Parma, em relação à proximidade entre a rainha e sua sobrinha. Tendo esta infanta recebido da tia várias peças de chita, a princesa das Astúrias não se conteve e comentou: «Irmã, estás muito bonita!» ${ }^{69}$.

No dia 12, Coutinho relatou o beija-mão que houve na corte, assinalando o aniversário de Carlos III e em que D. Mariana Vitória esteve, naturalmente, presente $^{70}$. A 14, mudaram-se para Santo Ildefonso ${ }^{71}$. A 22, a própria relatou a festa de aniversário do herdeiro do trono, comentando o aspeto dos elementos femininos da família real espanhola. A princesa das Astúrias, trazia «um toucado medonho», além de se achar «mal enfeitada, o vestido de brocado com muitas rendas de prata»e, no que dizia respeito às joias, «as pedras não são grandes e os diamantes pequenos». Já a infanta D. Maria Josefa mereceu os seus aplausos: os rubis que levava eram «muitos e de bom tamanho» ${ }^{72}$.

${ }^{67}$ B.A., 54-V-20 (8f). Sobre tudo o que diz respeito a interesse por animais e trocas de presentes entre as duas cortes ibéricas, cfr. Isabel M. R. Mendes Drumond Braga, "Descobrir e juntar animais: 'Novas novidades', Pátio dos Bichos e Jardim Zoológico de Lisboa”, em Animais e Companbia na História de Portugal, ed. Isabel Drumond Braga e Paulo Drumond Braga (Lisboa: Círculo de Leitores, 2015), 317-389.

68 A.N.T.T., Ministério dos Negócios Estrangeiros, caixa 629.

${ }^{69}$ A.N.T.T., Ministério dos Negócios Estrangeiros, caixa 630.

70 A.N.T.T., Ministério dos Negócios Estrangeiros, caixa 629.

71 A.N.T.T., Ministério dos Negócios Estrangeiros, caixa 629.

72 B.A., 54-V-20 (8v). 
Dias depois, em missiva não datada, D. Mariana Vitória voltou a falar da princesa das Astúrias: «não se pode chamar feia nem bonita», é «muito bem feita a agradável» e os «olhos são bons». Também se pronunciou sobre o palácio de Santo Ildefonso, onde então se achava: «é muito bom, grande e admiravelmente concertado de pinturas, espelhos», elogiando ainda os jardins, com fontes, cascatas e estátuas de bronze $^{73}$. A 24, voltou a salientar as atenções recebidas de Carlos III: «vem todas as manhãs ainda quando estou na cama». O tempo, entretanto, melhorara: "parecem os nossos dias formosos de Portugal» ${ }^{74}$.

Chegaram a Madrid a 2 de dezembro ${ }^{75}$. A 7, foi à Atocha ${ }^{76}$, e, em carta desse mesmo dia para D. Maria I, D. Mariana Vitória referiu-se ao palácio real de Madrid como demasiado grande: «as casas são grandíssimas e altura excessiva, eu gosto mais de casas mais pequenas, acomodam melhor a vista». O Escorial, no seu entender, «era mais cómodo». Classificou depois o bosque do Pardo como «lindo», acrescentando ser «muito parecido com a nossa tapada de Vila Viçosa». Quanto à Zarzuela, considerou-a «uma galante casa de campo e bem ornada» ${ }^{77}$. A 10 , transferiu-se para Aranjuez, sempre acompanhada da infanta D. Maria Josefa ${ }^{78}$. Dois dias volvidos, aludia, saudosa, ao «nosso Tejo», que passa atrás do palácio ${ }^{79}$.

A 22, Francisco Inocêncio de Sousa Coutinho anunciou que a rainha mãe acabara de fazer «um ato de generosidade muito necessário», dando 12 mil cruzados aos «criados menores da casa, mesa, cozinha e cavalariças» que a vinham servindo ${ }^{80}$.

No segundo dia de 1778, achando-se em Madrid, D. Mariana Vitória informou D. Maria I que se iriam mudar para o Pardo, sobre o qual «todos me dizem que é menos frio» ${ }^{81}$. A 12 de janeiro, referiu-se ao Pardo como «muito lindo e alegre». $\mathrm{E}$ aproveitou para se queixar do frio «cruel» que passara em Madrid, ironizando: «a minha pátria não me tratou bem» ${ }^{82}$. A 25 do mesmo mês, relatou à filha as tempestades que haviam fustigado algumas zonas de Espanha, de que resultara «perdas de muitas embarcações e de algumas vidas» ${ }^{83}$. A 8 de abril, ainda no Pardo, confessou: «de Madrid não gosto, acho muito triste». E manifestou o desejo de «conservar a vida» para poder tornar «a ver a toda a minha querida família» ${ }^{84}$. A 20 do mesmo mês, relatou que fora com Carlos III ver as igrejas quando da semana

\footnotetext{
73 B.A., 54-V-20 (8u).

${ }^{74}$ B.A., $54-\mathrm{V}-20$ (8i).

75 A.N.T.T., Ministério dos Negócios Estrangeiros, caixa 629.

76 A.N.T.T., Ministério dos Negócios Estrangeiros, caixa 629.

77 B.A., 54-V-20 (8g).

78 A.N.T.T., Ministério dos Negócios Estrangeiros, caixa 629.

${ }^{79}$ B.A., 54-V-20 (8j).

80 A.N.T.T., Ministério dos Negócios Estrangeiros, caixa 629.

${ }^{81}$ B.A., 54-V-20 (8k).

${ }^{82}$ B.A., $54-\mathrm{V}-20$ (8h).

${ }^{83}$ B.A., $54-\mathrm{V}-20$ (8n).

84 B.A., 54-V-20 (8r).
} 
santa madrilena («é magnífico pelo grande acompanhamento de criados, corte e soldados») e desabafou: «Estou com receio da jornada de Aranjuez» ${ }^{85}$.

A 30 de junho, Francisco Inácio de Sousa Coutinho escreveu que D. Mariana Vitória lhe manifestara as saudades pela família portuguesa «e quanta inveja lhes tem na assistência de Queluz». A 3 de agosto, o mesmo manifestou os seus receios pela longa jornada para Portugal. Dois dias depois, informou que a rainha fizera várias visitas em Madrid, tendo ido a uma fábrica de porcelana, ao palácio do Retiro «ver algumas peças», depois ao Prado e finalmente ao gabinete de história natural «de que se agradou muito». Nos primeiros dias de setembro, estante em Santo Ildefonso, visitou Segóvia, tendo estado no Alcazar e na escola dos cadetes ${ }^{86}$.

Uma testemunha da viagem de Mariana Vitória a Espanha, Jean-François de Bourgoing, que era então secretário da legação francesa, escreveu que a mesma «não conseguiu tornar-se agradável», sobretudo devido à sua altivez e aos seus caprichos. «Pouco acessível, provocou descontentamentos em todas as classes» e nem os ricos presentes que deixou no seu regresso a Portugal foram suficientes para compensar essa má impressão extrema ${ }^{87}$. O oposto escreveu Rodrigo de Sousa Coutinho: «todos admiram o seu grande juízo e desejavam que aparecesse mais vezes, pois que não quer deixar o retiro do nosso país, o que causa infinita pena a todos, pois todo o mundo se admira do seu grande juízo e a todos encanta a sua conversação» ${ }^{88}$.

O regresso de D. Mariana Vitória a Portugal começou a ser pensado no verão de 1778. Segundo informava, a 27 de agosto, o embaixador português, a mesma desejava de coração ir para junto das filhas, desagradando-lhe a perspetiva de passar novo inverno em Espanha, mas ao mesmo tempo receava a longa viagem ${ }^{89}$. A 8 de setembro, Lisboa era informada que D. Mariana Vitória pretendia empreender o regresso depois do dia de $\mathrm{S}$. Carlos, «se a saúde a não embaraçar» ${ }^{90}$. A 27 , o embaixador referiu que Carlos III pedira à infanta $\mathrm{D}$. Maria Josefa para mostrar a $\mathrm{D}$. Mariana Vitória o itinerário que propunha para a jornada, prevendo 12 dias do Escorial a Badajoz, para maior conforto da irmã ${ }^{91}$. A 30, foi dito por Sousa Coutinho que a rainha já se encontrava a tratar de tudo para a viagem. Por exemplo, «que as carruagens e fato deveriam ir até Elvas, aonde, e no tempo do jantar, se poderiam mudar para as carruagens portuguesas». Mariana Vitória confidenciara então ao embaixador que «ia para sua casa» e perguntou-lhe se sabia se as filhas, o genro e os netos a iriam esperar a Vila Viçosa ${ }^{92}$.

85 B.A., 54-V-20 (8x).

86 A.N.T.T., Ministério dos Negócios Estrangeiros, caixa 630.

87 [Comartin], Voyage, 95-96, nota 1.

88 Silva, Portrait, 390.

89 A.N.T.T., Ministério dos Negócios Estrangeiros, caixa 630.

${ }^{90}$ A.N.T.T., Ministério dos Negócios Estrangeiros, caixa 630.

91 A.N.T.T., Ministério dos Negócios Estrangeiros, caixa 630.

92 A.N.T.T., Ministério dos Negócios Estrangeiros, caixa 630. 
A 2 de outubro, dizia a prioresa de Carnide a D. Maria I: «confesso que estimo que sua mãe queira vir» ${ }^{93}$. Haveria da parte da rainha reinante de Portugal o receio de que D. Mariana Vitória não voltasse a Portugal, escolhendo a terra natal para passar os derradeiros dias de vida? No dia seguinte, era a vez de um diplomata inglês oficiar Londres que se esperava que D. Mariana Vitória deixasse Madrid em novembro ${ }^{94}$.

A 31 de outubro, falando com a irmã a respeito da sua partida, Carlos III «derramou bastantes lágrimas e exigiu da mesma senhora a promessa de voltar a vêlo dentro de dois ou três anos». A 4 de novembro, trocaram presentes ${ }^{95}$. Entre estes, conta-se o da princesa das Astúrias à sua tia de Portugal, que consistiu numa gaiola com um canário «que canta, move e garganteia e anda de um lado a outro, como se realmente fosse vivo ao impulso da máquina e corda que se lhe dá». Já a rainha-mãe de Portugal teve idênticas gentilezas, ofertando, por exemplo, à infanta D. Maria Josefa, um adereço de grisolitas e diamantes e umas manilhas de brilhantes. Não esqueceu as duas netas de Carlos III, Carlota Joaquina - futura rainha de Portugal, então criança de três anos de idade -, a quem deu um pluma de esmeraldas e diamantes, e Maria Luísa - de apenas um ano - , que recebeu uma pluma de diamantes e rubis ${ }^{96}$.

A viagem rumo a Portugal começou às nove horas da manhã de dia 5 desse mês de novembro de 1778. «A despedida foi muito terna», lê-se num ofício de Sousa Coutinho. Carlos III, ainda que solicitado por Mariana Vitória a permanecer nos seus aposentos, preferiu ir até à entrada da sege: «se abraçou novamente com a sua augusta irmã e se recolheu depois que a mesma senhora partiu, deixando nos olhos as provas fiéis do seu extremoso coração». Era a derradeira vez que se viam. No dia seguinte, a comitiva estava em Casarubias del Monte. «Para enganar as saudades de duas cortes que tanto interessam ao seu régio coração», convenceram-na a jogar o 31, como habitualmente fazia todas as noites. A jornada continuou e a 13 chegaram a Talavera, tendo D. Mariana Vitória visitado várias fábricas. O embaixador regressou então ao Escorial ${ }^{97}$.

Entretanto, do outro lado da fronteira, D. Maria I, D. Pedro III, os príncipes D. José e D. Maria Francisca Benedita e a infanta D. Maria Ana Josefa Francisca partiram, a 9 de novembro, de Lisboa, rumo a Vila Viçosa, passando por Aldeia Galega $^{98}$. Chegaram a Vila Viçosa na noite de 11 para $12^{99}$. A 18 , rumaram os reis e os príncipes a Elvas, ao encontro da rainha-mãe, tendo D. Maria I e D. Pedro III

\footnotetext{
${ }^{93}$ Lázaro, O Reinado, 372.

94 Boxer, Descriptive, 253.

95 A.N.T.T., Ministério dos Negócios Estrangeiros, caixa 630.

${ }^{96}$ Gama, "Crónica", 245-246.

${ }^{97}$ A.N.T.T., Ministério dos Negócios Estrangeiros, caixa 630

98 Gazeta de Lisboa, n. ${ }^{\circ}$ 15, Lisboa, 10 de novembro de 1778.

${ }_{99}$ Gazeta de Lisboa, n. ${ }^{\circ}$ 16, Lisboa, 17 de novembro de 1778.
} 
mandado os respetivos camareiros-mores cumprimentar Mariana Vitória a Badajoz. No dia seguinte, toda a família presente dirigiu-se ao Caia. Começaram a aglomerarse Portugueses e Espanhóis. Segundo comentário do $2 .^{\circ}$ conde de Oeiras, filho do antigo valido de D. José I, «algumas das fidalgas castelhanas que se achavam nos coches se apearam arrebatadamente dos ditos coches para verem o príncipe [do Brasil, D. José] de mais perto e, não se contentando com vê-lo, lhe foram beijar a mão» ${ }^{100}$. Pelas 10 horas da manhã, Mariana Vitória atravessou o rio na sua sege, seguida de coches e cavaleiros espanhóis. Filhas, genro e netos apearam-se das carruagens para a acolher. Assim que os viu, a rainha quis fazer o mesmo,

porém achando-se alguma coisa trôpega e não estando ali logo pronto o degrau para descer da carruagem, chegou el rei [D. Pedro III] ainda a tempo de pegar em Sua Majestade por uma parte e alguns dos camaristas que ali se achavam mais perto pela outra pegaram na mesma senhora quase ao colo para a apoiarem, e ao tempo de Sua Majestade descer da carruagem chegou a rainha nossa senhora [D. Maria I] e suas sereníssimas irmãs e ajoelhando todas as meio daquele arraial a abraçaram e lhe beijaram a mão, com os olhos cheios de lágrimas, alegres (ato que nos enterneceu a todos) e que também nos fez deitar nossas lágrimas de alegria ${ }^{101}$.

D. Maria I e D. Pedro III entraram então numa das seges, D. Mariana Vitória, D. José, D. Maria Francisca Benedita e D. Maria Ana Josefa Francisca noutra e rumaram a Elvas e depois a Vila Viçosa, onde chegaram a 21. A 10 de dezembro, empreenderam a viagem de regresso a Lisboa, indo por Évora, onde permaneceram alguns dias. Estavam na capital a 14, recolhendo ao palácio da Ajuda entre as 15 e as 16 horas $^{102}$. A 17, o aniversário de D. Maria I foi «ainda mais festivo» dada a «apetecida presença de sua augusta mãe» ${ }^{103}$.

D. Mariana Vitória pouco tempo sobreviveu a esta viagem. Veio a morrer a 15 de janeiro de 1781, próximo de completar 63 anos de idade, provavelmente vitimada por uma insuficiência cardíaca causada por pneumopatia. Jaz na igreja de S. Francisco de Paula, em Lisboa ${ }^{104}$.

100 B.N.P., Coleção Pombalina, n. ${ }^{\circ}$ 692, f. 161.

101 B.N.P., Coleção Pombalina, n. ${ }^{\circ}$ 692, f. 161v.

102 Gazeta de Lisboa, Suplemento ao n. ${ }^{\circ}$ 18, Lisboa, 4 de dezembro de 1778; suplemento ao n. ${ }^{\circ} 19$, 11 de dezembro; n. ${ }^{\circ} 20,15$ de dezembro.

103 Gazeta de Lisboa, Suplemento ao n. ${ }^{\circ}$ 20, Lisboa, 18 de dezembro de 1778.

104 Braga, A Rainha, 238-242. 


\section{FONTES E BIBLIOGRAFIA}

\section{Fontes manuscritas:}

Archivo General de Simancas (A.G.S.), Estado, leg. 2512, 4683, 7161, 7297

Archivo Historico Nacional (A.H.N.), Estado, leg. 3410, expediente 1, n. 11 (1 e 2).

Arquivo Nacional da Torre do Tombo (A.N.T.T.), Ministério dos Negócios Estrangeiros, caixas 629, 630 e 826.

Biblioteca da Ajuda (B.A.), 54-V-20 (8a-8x); 54-X-7 (159).

Biblioteca Nacional de Portugal (B.N.P)., Coleção Pombalina, n. ${ }^{\circ} 692$

\section{Fontes impressas:}

Caetano Beirão, Cartas da Raínha D. Mariana Vitória para a sua Família de Espanha que se encontram nos Arquivos Histórico de Madrid e Geral de Simancas, vol. I, Lisboa: Empresa Nacional de Publicidade, 1936.

Jeremy Black, "Portugal in 1775. The letters of Thomas Pelham", The British Historical Society of Portugal 14 (1987), 49-55.

Marquis de Bombelles, Journal d' un Ambassadeur de France an Portugal. 1786-1788, Paris: Fundação Calouste Gulbenkian, 1979.

C. R. Boxer, Descriptive List of the State Papers Portugal 1661-1780 in the Public Record Office London, vol. III, Lisboa: Academia das Ciências de Lisboa, 1983.

Alfred Braudillart, Philippe $V$ et la Cour de France d'après des Documents Inédites tirès des Archives Espagnols de Simancas et d'Alcalá d'Henarés et des Archives du Ministére des Affaires Étrangères à Paris, tomo III, Paris: Fitmin-Didor, 1890.

Cartas do Marquês de Pombal (1777-1780), Coimbra: Imprensa da Universidade, 1916.

[Pierre Marie Félicité Dezoteux, barão de Comartin], Voyage du ci-devant Duc de Chatelet en Portugal, tomo I, Paris : Arthus-Betrand, 1808.

Charles Dumouriez, État Présent du Royaume de Portugal en l'Année MDCCLXVI, Lausanne: François Grasset, 1775.

António Pereira de Figueiredo, Diario dos Successos de Lisboa desde o Terramoto até o Exterminio dos Jesuitas, Lisboa: Francisco Borges de Sousa, 1766. 
Eurico Gama, "Crónica da viagem da Rainha mãe de Portugal, Dona Mariana Vitória de Bourbon, a Espanha, no Outono de 1777”, Ocidente 176 (1952), 239-249.

Gazeta de Lisboa, n. ${ }^{\circ}$ 15, 10 de novembro de 1778; n. ${ }^{\circ}$ 16, 17 de novembro de 1778; Suplemento ao n. ${ }^{\circ} 18,4$ de dezembro de 1778; suplemento ao n. ${ }^{\circ} 19,11$ de dezembro; n. ${ }^{\circ}$ 20, 15 de dezembro; Suplemento ao n. ${ }^{\circ}$ 20, 18 de dezembro de 1778 .

Giuseppe Gorani, Portugal. A Corte e o País nos anos de 1765 a 1767, Lisboa: Lisóptima, 1989.

José Pedro Ferrás Gramoza, Successos de Portugal. Memorias Historicas Politicas e Civis, tomo II, Lisboa: Tipografia do Diário da Manhã, 1882.

Alice Lázaro, O Reinado do Amor. Cartas Íntimas da Priora da Estrela para a Rainha Dona Maria I (1776-1780), Lisboa: Chiado, 2013.

Conde de Saint-Priest, "Um campanha militar. 1762. Uma missão diplomática. 17631766", Portugal nos Séculos XVII \& XVIII. Quatro Testemunhos, Lisboa: Lisóptima, 1989, 127-157

Margarita Torrione, Lucienne Domergue, Reyes Escalera Pérez, José Miguel Morales Folguera, Marion Reder Gadow, Crónica Festiva de dos Reinados en la Gaceta de Madrid (1700-1759), Toulouse: Universidade de Toulouse-Le Mirail, Paris: Ophris, 1998.

\section{Estudos:}

Maria Isabel Braga Abecassis, A Real Barraca. A Residência na Ajuda dos reis de Portugal após o Terramoto (1756-1794), Lisboa: Tribuna da História, 2009.

Michel Antoine, Louis XV, Paris: Hachette, 2006.

Raquel Bello Vázquez, "Uma Certa Ambição de Glória: Trajectória, Redes e Estratégias de Teresa de Mello Breyner nos Campos Intelectual e do Poder em Portugal (1770-1798)" Tese de doutoramento, Universidade de Santiago de Compostela, 2005.

Isabel M. R. Mendes Drumond Braga, "Descobrir e juntar animais: 'Novas novidades', Pátio dos Bichos e Jardim Zoológico de Lisboa", em Animais e Companbia na História de Portugal, ed. Isabel Drumond Braga e Paulo Drumond Braga, Lisboa: Círculo de Leitores, 2015, 317-389. 
Paulo Drumond Braga, A Rainha Discreta. Mariana Vitória de Bourbon, Lisboa: Círculo de Leitores, 2014.

José de Castro, O Cardial Nacional, Lisboa: Agência Geral das Colónias, 1943.

Henry Kamen, Felipe V. El Rey que reinó dos veces, Madrid: Temas de Hoy, 2000.

María Victoria López-Cordón Cortezo, "Mariana Victoria de Portugal: una infanta y muchas cartas”, Pedralbes 36 (2016), 17-53.

Alexandre Maral, Le Roi, la Court et Versailles. Le Coup d'Eclat Permanent. 1682-1789, Paris: Perrin, 2013.

Filipe Folque de Mendonça, O Cardeal Patriarca de Lisboa Dom José de Mendonça. O Homem e o seu Tempo (1725-1808), Lisboa: Universidade Lusíada, 2010.

Nuno Gonçalo Monteiro, D. José na Sombra de Pombal, Lisboa: Círculo de Leitores, 2006.

María de los Ángeles Pérez Samper, "Princesas en camino", Estudis. Revista de Historia Moderna 39 (2013), 9-41.

Jennifer Roberts, The Madness of Queen Maria. The Remarkable Life of Maria I of Portugal, Langely Burrell: Templeton, 2009.

Visconde de Santarém, Quadro Elementar as Relações Politicas e Diplomaticas de Portugal com as Diversas Potencias do Mundo, tomos VI, Paris: J. P. Aillaud, 1864 e VII, Paris: J. P. Aillaud, 1865.

Andrée Mansuy-Diniz Silva, Portrait d'un Homme d'État: D. Rodrigo de Sousa Coutinho, Comte de Linhares. 1755-1812, vol. I, Lisboa: Comissão Nacional para as Comemorações dos Descobrimentos Portugueses; Paris: Centro Cultural Calouste Gulbenkian, 2002.

Recibido: 21 de junio de 2018 Aprobado: 27 de octubre de 2018 